University of Nebraska - Lincoln

DigitalCommons@University of Nebraska - Lincoln

Faculty Publications from the Department of Electrical \& Computer Engineering, Department Electrical and Computer Engineering

8-9-2004

\title{
Laser-assisted nanoscale deposition of diamond-like carbon films on tungsten tips
}

\author{
J. Shi \\ University of Nebraska-Lincoln \\ Yongfeng Lu \\ University of Nebraska-Lincoln, ylu2@unl.edu \\ R. S. Cherukuri \\ University of Nebraska-Lincoln \\ K. K. Mendu \\ University of Nebraska-Lincoln \\ D. W. Doerr \\ University of Nebraska-Lincoln \\ See next page for additional authors
}

Follow this and additional works at: https://digitalcommons.unl.edu/electricalengineeringfacpub

Part of the Electrical and Computer Engineering Commons

Shi, J.; Lu, Yongfeng; Cherukuri, R. S.; Mendu, K. K.; Doerr, D. W.; Alexander, Dennis R.; Li, L. P.; and Chen, X. Y., "Laser-assisted nanoscale deposition of diamond-like carbon films on tungsten tips" (2004). Faculty Publications from the Department of Electrical and Computer Engineering. 98.

https://digitalcommons.unl.edu/electricalengineeringfacpub/98

This Article is brought to you for free and open access by the Electrical \& Computer Engineering, Department of at DigitalCommons@University of Nebraska - Lincoln. It has been accepted for inclusion in Faculty Publications from the Department of Electrical and Computer Engineering by an authorized administrator of DigitalCommons@University of Nebraska - Lincoln. 


\section{Authors}

J. Shi, Yongfeng Lu, R. S. Cherukuri, K. K. Mendu, D. W. Doerr, Dennis R. Alexander, L. P. Li, and X. Y. Chen 


\title{
Laser-assisted nanoscale deposition of diamond-like carbon films on tungsten tips
}

\author{
J. Shi, Y. F. Lu, ${ }^{\text {a) }}$ R. S. Cherukuri, K. K. Mendu, D. W. Doerr, D. R. Alexander, and L. P. Li \\ Department of Electrical Engineering, University of Nebraska-Lincoln, Lincoln, \\ Nebraska 68588-0511 \\ X. Y. Chen \\ Department of Electrical and Computer Engineering, National University of Singapore, \\ 10 Kent Ridge Crescent, Singapore 119260, Singapore
}

(Received 12 March 2004; accepted 8 June 2004)

\begin{abstract}
Diamond-like carbon (DLC) films were deposited on tungsten tips under $\mathrm{KrF}$ excimer laser irradiation in benzene solution. The deposition process was found to be highly dependent on tip sharpness. Tips with larger curvature radii and smaller aspect ratios could not be coated with DLC films under the same condition as that for sharp tips. Raman spectra showed that more $\mathrm{sp}^{3}$ tetrahedral structures were present in the DLC films on a tip with a smaller curvature radius. Simulation results showed that the tip sharpness dependent local optical enhancement played an important role in the DLC deposition process. An optical field gradient from apex to tip body was also found in the simulation. We suggest that there are two modes in the process of DLC deposition on nanotips under different laser fluences, i.e., local apex DLC deposition under low laser fluences and phase-graded DLC deposition under high laser fluences. (C) 2004 American Institute of Physics. [DOI: $10.1063 / 1.1777816]$
\end{abstract}

Diamond-like carbon (DLC) coated tips have been successfully applied in field emitter array, ${ }^{1-3}$ scanning spreading resistance microscopy (SSRM) ${ }^{4}$ and showed great potential in scanning probe microscope (SPM) based nanofabrications, such as dip-pen lithography, ${ }^{5,6}$ laser assisted SPM nanostructuring ${ }^{7-9}$ and nanografting. ${ }^{10}$ Conventional techniques for DLC deposition on sharp tips include hot-filament chemical vapor deposition, ${ }^{11,12}$ microwave plasma chemical vapor deposition, ${ }^{13}$ filtered catholic vacuum arc deposition, ${ }^{14}$ and pulsed laser deposition. ${ }^{2}$

In this letter, we present an alternative approach, using a laser-assisted method for sharp tip DLC deposition in liquid benzene. As predicted by near-field theory, ${ }^{15-17}$ a strongly enhanced and locally confined optical field will be formed around the tip apex under laser irradiation. Therefore, this method distinguishes itself from the conventional DLC deposition methods and other laser-assisted deposition methods on flat surfaces ${ }^{18-20}$ that a locally confined DLC deposit within nanometer scale range from the apex can be potentially achieved. In this work, a tip sharpness dependent deposition was observed. Based on the optical simulations, the effect of tip sharpness (curvature radius and aspect ratio- the ratio of the height of the cone and the radius of the base) on enhancement factor and structural properties of the DLC films is discussed. Two DLC deposition modes, highly confined local apex DLC deposition and phase-graded DLC deposition are suggested.

Tungsten tips were fabricated using DC electrochemical etching of tungsten wires $(0.5 \mathrm{~mm}$ in diameter $)$ in a $2 \mathrm{~N} \mathrm{KOH}$ solution. ${ }^{21}$ By controlling the length of the $\mathrm{W}$ wire dipped in the $\mathrm{KOH}$ solution, a group of tips with different radii of curvature and aspect ratios were made. The bottom part of the tungsten tip was adhered on a carbon tape attached to a glass slide. Several benzene droplets were dropped to cover the tip apex region. The carbon tape was

\footnotetext{
${ }^{a)}$ Electronic mail: ylu2@unl.edu
}

used as a spacer to ensure that the apex of the tip was immersed in the benzene liquid. A KrF excimer laser (Lambda Physik Compex 205, wavelength $=248 \mathrm{~nm}$, pulse duration $=23 \mathrm{~ns}$ ) was used to irradiate the tips with a single pulse. The incident direction was normal to the tip cone axis. The apex of each tip was aligned at the center of the laser beam each time. A Hitachi S-4700 field emission scanning electron microscope (FESEM) was used for morphological characterization. The structures of the deposited DLC films on the tips were characterized by a micro-Raman spectroscope which was excited by an argon ion laser at $514.5 \mathrm{~nm}$. High frequency structure simulator (HFSS v9.0 Ansoft, Inc.) was used to simulate the optical field around the tip apexes. Tips were modeled as cones with different curvature radii and aspect ratios, contained in a benzene cuboid. The incident optical wave was set to be a $p$-polarized plane wave at $248 \mathrm{~nm}$ with the incident direction normal to the cone axis; the electrical field vector was along the cone axis with a unit magnitude. The complex dielectric constants of tungsten and benzene at $248 \mathrm{~nm}$ were set to $3.37+19.3 i$ and 1.62 , respectively, by interpolation of the data from Refs. 22 and 23.

Table I lists the tips with different curvature radii, aspect ratios and laser fluences used in this work. SEM micrographs of tungsten tips 1-3 after a single laser pulse were shown in Figs. 1(a)-1(c) respectively. In Fig. 1(a), the surface of tip 1 was coated with a layer of DLC, on which nanosized particles with diameters ranging from 10 to $50 \mathrm{~nm}$ could be found. The curvature radius of tip 1 was around $100 \mathrm{~nm}$ and

TABLE I. Curvature radii, aspect ratios, and laser fluences for different tips.

\begin{tabular}{cccc}
\hline \hline Sample & $\begin{array}{c}\text { Curvature radius } \\
(\mathrm{nm})\end{array}$ & Aspect ratio & $\begin{array}{c}\text { Laser fluence } \\
\left(\mathrm{mJ} / \mathrm{cm}^{-2}\right)\end{array}$ \\
\hline Tip 1 & 100 & 3 & 187 \\
Tip 2 & 153 & 3.5 & 230 \\
Tip 3 & 480 & 2 & 230 \\
\hline \hline
\end{tabular}



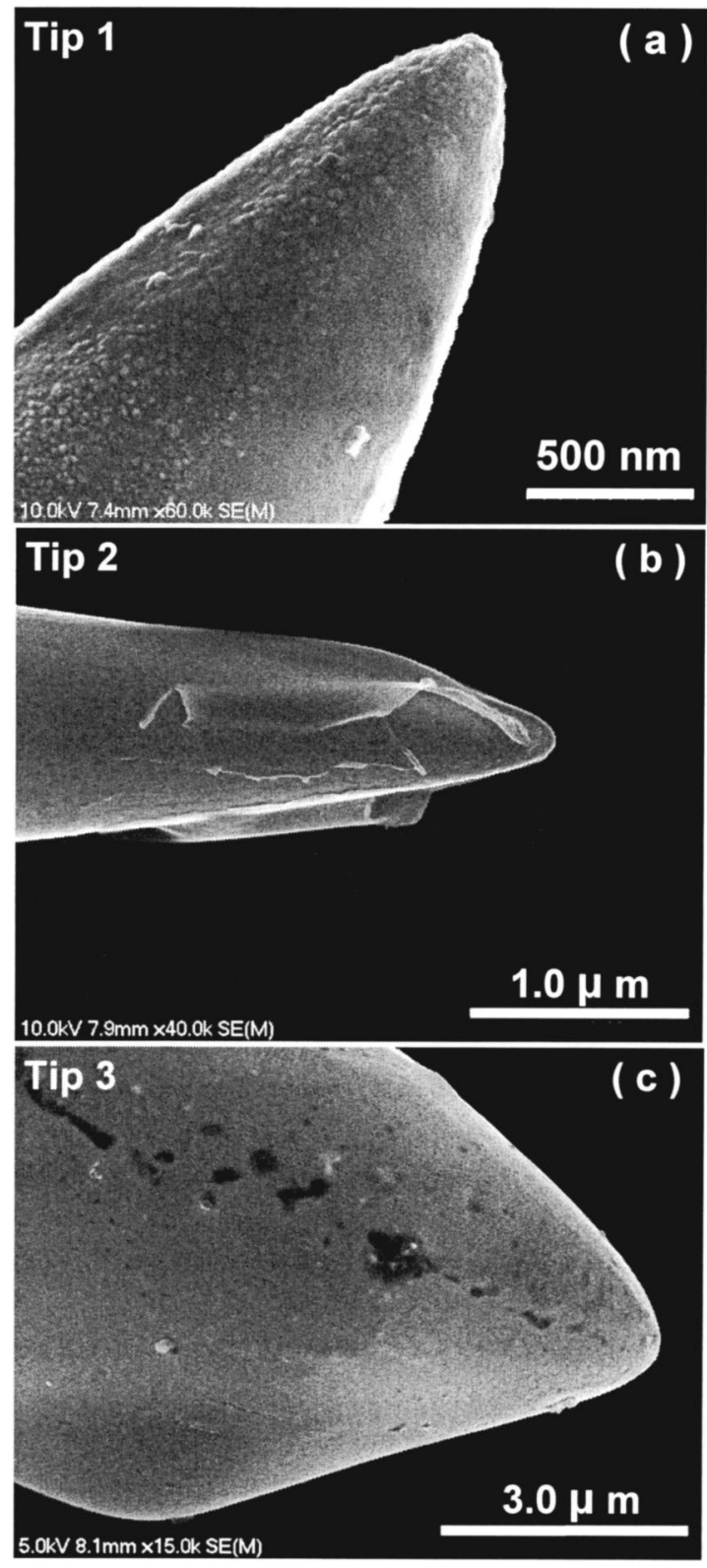

FIG. 1. SEM micrographs of the tungsten tips after laser irradiation in benzene solution (a) tip 1 with a curvature radius of $100 \mathrm{~nm}$, aspect ratio of 3 under a laser fluence of $187 \mathrm{~mJ} / \mathrm{cm}^{-2}$; (b) tip 2 with a curvature radius of $153 \mathrm{~nm}$, aspect ratio of 3.5 under a laser fluence of $230 \mathrm{~mJ} / \mathrm{cm}^{-2}$; and (c) tip 3 with a curvature radius of $480 \mathrm{~nm}$, aspect ratio of 2 under a laser fluence of $230 \mathrm{~mJ} / \mathrm{cm}^{-2}$.

the aspect ratio was around 3. The DLC film thickness at the apex was around $40 \mathrm{~nm}$. In Fig. 1(b), a thin DLC layer was coated outside the tip apex, the thickness of which was less than $20 \mathrm{~nm}$. The curvature radius of tip 2 was reduced to $150 \mathrm{~nm}$ and the aspect ratio was increased to 3.5. The smooth layer deposited on tip 2 indicates a dominant amorphous phase in the DLC film. This layer was confined within $2 \mu \mathrm{m}$ from the tip apex. In Fig. 1(c), no deposition can be observed on tip 3 . The curvature radius of tip 3 was increased to $480 \mathrm{~nm}$ and the aspect ratio was reduced to around 2. Raman spectra of tips 1 and 2 are shown in Fig. 2. The Raman spectrum of tip 1 was Gaussian fitted, in which two peaks at 1390 and $1571 \mathrm{~cm}^{-1}$ were identified as $D$ and $G$ bands, respectively. The $I(D) / I(G)$ ratio is around 0.98 indicating a substantial amount of $\mathrm{sp}^{3}$ diamond-like structures in the film. ${ }^{18,19}$ The Raman spectrum of tip 2 shows no peak. $\begin{array}{lllllll}800 & 1000 & 1200 & 1400 & 1600 & 1800 & 2000\end{array}$

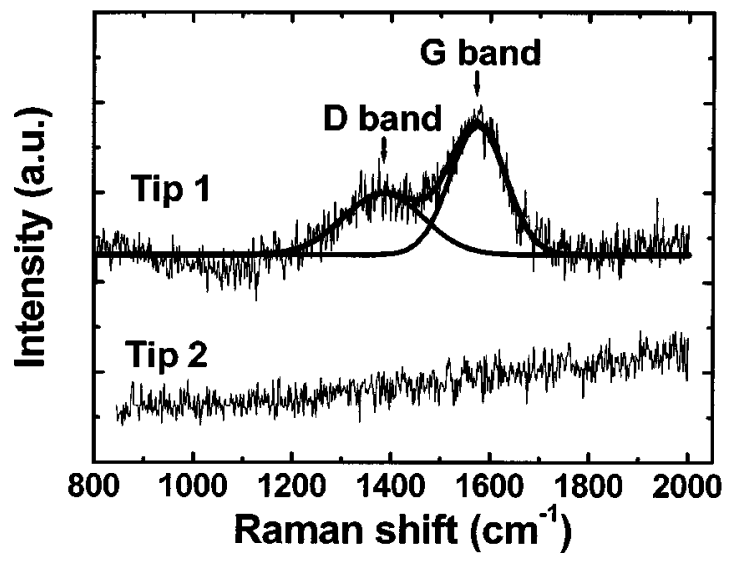

FIG. 2. Raman spectra for DLC films deposited on tungsten tips 1 and 2 .

This could be due to the fact that the DLC film on tip 2 was too thin to generate sufficient Raman scattering. As shown in Table I, the laser fluence used to irradiate tip 1 was $187 \mathrm{~mJ} / \mathrm{cm}^{-2}$, which was smaller than the fluence of $230 \mathrm{~mJ} / \mathrm{cm}^{-2}$ for tips 2 and 3 . The fact that no DLC deposition took place on tip 3 indicates that a fluence of $230 \mathrm{~mJ} / \mathrm{cm}^{-2}$ is not sufficient for effective thermal decomposition of benzene, because tip 3 had the largest curvature radius and the smallest aspect ratio. For tip 2, when the tip curvature radius was reduced to $153 \mathrm{~nm}$ and aspect ratio was increased to 3.5, DLC film was deposited under the same fluence as that for tip 3. The deposited film was mainly in amorphous phase. For tip 1, as the curvature radius was further reduced to $100 \mathrm{~nm}$ (aspect ratio kept around 3), the deposited film was more diamond-like even at a lower laser fluence $\left(187 \mathrm{~mJ} / \mathrm{cm}^{-2}\right)$. From these experimental data, we find that tip curvature radius and aspect ratio play important roles in DLC deposition on tips. We suggest that there be a much stronger local optical intensity at the sharper tips than the blunt tips under the same laser fluence. At certain laser fluences, DLC can be selectively deposited only onto sharp tips. Deposited films tend to be more diamond-like as the tips become sharper.

Figure 3 shows the simulation results of the optical field around tungsten tips contained in a benzene cuboid under a plane wave irradiation. Figures 3(a) and 3(b) are $Y Z$ and $X Z$ cross sections of the electrical field ( $E$ field) around tip apex with a curvature radius of $10 \mathrm{~nm}$ and an aspect ratio of 3 . A region with a strongly enhanced $E$ field was locally formed, extending to $100 \mathrm{~nm}$ from the apex. The highest $E$-field enhancement factor at the apex was around 9.5 (equivalent to an optical intensity enhancement of 91). Figure 3(c) shows the field distribution of a tip with a curvature radius of $70 \mathrm{~nm}$ and an aspect ratio of 3 . Compared with the $E$-field distribution shown in Fig. 3(a), the highest $E$-field enhancement factor at the apex, as shown in Fig. 3(c), decreases from 9.5 to 5 , as the curvature radius is increased from 10 to $70 \mathrm{~nm}$. The enhanced field was confined to a region $35 \mathrm{~nm}$ from the tip apex. Figure 3(d) shows a tip with a curvature radius of $10 \mathrm{~nm}$ and an aspect ratio of 1 . E-field enhancement at the apex decreases from 9.5 to 7 as the aspect ratio of the tip decreases from 3 to 1 .

From the simulation results of $E$-field distribution, we found that the field enhanced regions were within $100 \mathrm{~nm}$ from the tip apexes. There was an enhancement gradient 

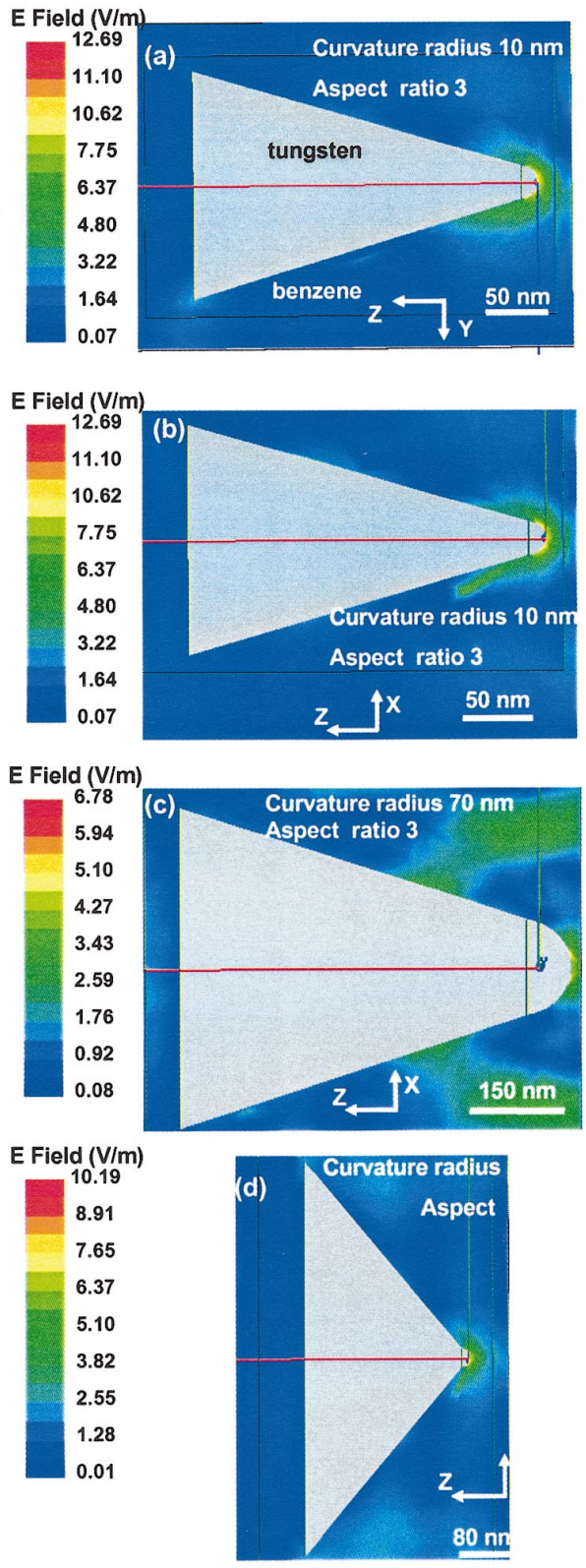

FIG. 3. (Color) Cross sectional view of the simulated $E$-field distribution around the apex vicinity. The incident wave direction is along $Y$ axis. The cone is the tungsten tip, enclosed in a rectangular benzene box. (a) $Z Y$ cross-sectional view of a tip with a curvature radius of $10 \mathrm{~nm}$, aspect ratio of 3; (b) $Z X$ cross sectional view of the same setup as (a); (c) $Z X$ cross sectional view tip with a curvature radius of $70 \mathrm{~nm}$, aspect ratio of 3 ; and (d) $Z X$ cross sectional view of tip with a curvature radius of $100 \mathrm{~nm}$, aspect ratio of 1 .

within each field enhanced region from the apex towards the tip body [as shown in Figs. 3(a)-3(d)]. This indicates that for a sharp tip, by varying the laser fluences, there will be two different modes for the DLC deposition. (1) When the laser fluence is sufficiently low, only the local optical intensity at the apex (where the optical field is highest) is sufficient for DLC deposition, a tightly confined nanoscale local deposition of DLC can be achieved. This local coating of DLC films will keep the sharpness of the tips and meanwhile provide the tips with a high wear resistance. (2) When the laser fluence is high, DLC films can be deposited on tip bulk surface, where there is almost no enhancement in optical field. A phase-graded DLC film can be deposited on the tip, with the apex region more diamond-like and extends gradually to the tip body with amorphous-like carbon films. Therefore, theoretically, by varying the tip curvature radius, aspect ratio and laser fluences, both nanoscale local DLC deposition and phase-graded DLC deposition can be achieved.

In summary, a method employing the optical near-field effects was used to deposit DLC films on the apexes of tungsten tips under laser irradiation. The deposition process was strongly dependent on the tip sharpness (the curvature radius and the aspect ratio). Simulation results indicated that an optically-enhanced region was formed at the apex region during laser irradiation. The enhancement factor dropped when the tip curvature radius was increased and aspect ratio was decreased. Simulation of the field distribution also showed an enhancement gradient from tip apex to tip body. We suggest that for tips with certain curvature radius and aspect ratio, by varying the laser fluences, there are two different modes for DLC deposition. At low laser fluences, nanoscale local deposition of DLC on tip apex can be achieved. At high laser fluences, phase-graded DLC deposition can be achieved.

This project was partly funded by Layman Award 2003 from the Layman Foundation. The authors thank Dr. Kit Lee who is from the Department of Biology at University of Nebraska-Lincoln for the SEM measurements.

${ }^{1}$ J. Chen, J. C. She, N. S. Xu, S. E. Huq, and S. Z. Deng, Appl. Phys. Lett. 81, 4257 (2002).

${ }^{2}$ F. Y. Chuang, C. Y. Sun, H. F. Cheng, C. M. Huang, and I. N. Lin, Appl. Phys. Lett. 68, 1666 (1996).

${ }^{3}$ J. H. Jung, Y. L. Nam, J. Jang, M. H. Oh, and S. Ahn, J. Vac. Sci. Technol. B 18, 933 (2000).

${ }^{4}$ D. Alvarez, J. Hartwich, M. Fouchier, P. Eyben, and W. Vandervorst, Appl. Phys. Lett. 82, 1724 (2003).

${ }^{5}$ R. D. Piner, J. Zhu, F. Xu, S. Hong, and C. A. Mirkin, Science 283, 661 (1999).

${ }^{6}$ S. Hong and C. A. Mirkin, Science 288, 1808 (2000).

${ }^{7}$ J. Jersch and K. Dickmann, Appl. Phys. Lett. 68, 868 (1996).

${ }^{8}$ Y. F. Lu, Z. H. Mai, G. Qiu, and W. K. Chim, Appl. Phys. Lett. 75, 2359 (1999).

${ }^{9}$ Z. H. Mai, Y. F. Lu, W. D. Song, and W. K. Chim, Appl. Surf. Sci. 154-155, 360 (2000).

${ }^{10}$ J. F. Liu, J. R.V. Ehr, C. Baur, R. Stallcup, J. Randall, and K. Bray, Appl. Phys. Lett. 84, 1359 (2004).

${ }^{11}$ G. Tanasa, O. Kurnosikov, C. F. J. Flipse, J. G. Buijnsters, and W. J. P. V. Enckevort, J. Appl. Phys. 94, 1699 (2003).

${ }^{12}$ P. Niedermann, W. Hanni, N. Blanc, R. Christoph, and J. Burger, J. Vac. Sci. Technol. A 14, 1233 (1996).

${ }^{13}$ S. Albin, J. Zheng, J. B. Cooper, W. Fu, and A. C. Lavarias, Appl. Phys. Lett. 71, 2848 (1997).

${ }^{14}$ N. S. Xu, J. C. She, S. E. Huq, J. Chen, and S. Z. Deng, Appl. Phys. Lett. 73, 3668 (1998)

${ }^{15}$ O. J. F. Martin and C. Girard, Appl. Phys. Lett. 70, 705 (1997).

${ }^{16}$ L. Novotny, R. X. Bian, and X. S. Xie, Phys. Rev. Lett. 79, 645 (1997).

${ }^{17}$ Y. F. Lu, Z. H. Mai, and W. K. Chim, Jpn. J. Appl. Phys., Part 1 38, 5910 (1999).

${ }^{18}$ Y. F. Lu, S. M. Huang, X. B. Wang, and Z. X. Shen, Appl. Phys. A: Mater. Sci. Process. 66, 543 (1998).

${ }^{19}$ Y. F. Lu, S. M. Huang, C. H. A. Huan, and X. F. Luo, Appl. Phys. A: Mater. Sci. Process. 68, 647 (1999).

${ }^{20}$ J. Singh, M. Vellaikal, and J. Narayan, J. Appl. Phys. 73, 4351 (1993).

${ }^{21}$ J. P. Ibe, P. P. Bey, Jr., S. L. Brandow, R. A. Brizzolara, N. A. Burnham, D. P. Dilella, K. P. Lee, C. R. K. Marrian, and R. J. Colton, J. Vac. Sci. Technol. A 8, 3570 (1990).

${ }^{22}$ E. D. Palik, Handbook of Optical Constants of Solids (Academic, Boston, 1985).

${ }^{23}$ A. Samoc, J. Appl. Phys. 94, 6167 (2003). 